\title{
Central delay of the laser-activated rat tail-flick reflex
}

\author{
Peggy J. Danneman a,*, Judith A. Kiritsy-Roy ${ }^{\text {b,d }}$, Thomas J. Morrow b,c,d, Kenneth L. Casey b,c,d \\ "Unit for Laboratory Animal Medicine and Departments of ${ }^{b}$ Neurology and" Physiology, The Unitersity of Michigan, Ann Arbor, \\ MI 48109 (USA) and "Veterans Affairs Medical Center, Ann Arbor, MI 48105 (USA) \\ (Received 18 June 1993, revision received 16 November 1993, accepted 23 November 1993)
}

\begin{abstract}
Summary
The latency of the heat-activated rat tail-flick (TF) reflex is dependent upon 4 variables, none of which has previously been determined: activation of cutaneous nociceptors $\left(\mathrm{T}_{\mathrm{N}}\right)$; afferent conduction to the dorsal horn $\left(T_{A}\right)$; conduction within the central nervous system (CNS) (central delay); and conduction from the ventral horn $(\mathrm{VH})$ to, and activation of, tail muscles $\left(\mathrm{T}_{\mathrm{E}}\right)$. Using a $\mathrm{CO}_{2}$ infrared laser $(10 \mathrm{~W}, 45 \mathrm{msec})$ to produce synchronous activation of tail-skin nociceptors, TF latency (EMG response) was measured in 10 awake rats. Based on shifts in response latency from points of stimulation near the tip and base of the tail, conduction velocity in the afferent limb of the reflex was estimated to be $0.76 \pm 0.11 \mathrm{~m} / \mathrm{sec}$. This indicates that the response is mediated by $\mathrm{C}$ fibers. The rats were then anesthetized with pentobarbital and multiple-unit activity and evoked potentials (EPs) were recorded from the superficial dorsal horn at spinal segments $\mathrm{S}_{3}-\mathrm{Co}_{1}$ during laser or high-intensity electrical ( 10 $\mathrm{mA}, 1 \mathrm{msec}$ ) stimulation of the tail. Unit activity and EPs elicited by both stimuli consisted of two distinct components, corresponding to activation of $\mathrm{A}$ and $\mathrm{C}$ fibers. The difference in latency between laser and electrical evoked activity indicated that $60.00 \pm 7.33 \mathrm{msec}$ was required for activation of nociceptors by the laser. Electrical stimulation of the $\mathrm{VH}$ at $\mathrm{S}_{3}-\mathrm{Co}_{1}$ in 3 rats produced a TF (EMG) response in 4 msec. Central delay, calculated as total $\mathrm{TF}$ time minus $\left(\mathrm{T}_{\mathrm{N}}+\mathrm{T}_{\mathrm{A}}+\mathrm{T}_{\mathrm{E}}\right)$, was $82.3 \pm 13.08 \mathrm{msec}$. This represents the time frame during which modulation of the reflex by an intrinsic, pain-activated, supraspinal system could occur.
\end{abstract}

Key words: 'Iail-flick reflex; Dorsal horn; Central delay; $\mathrm{C}$ fiber; A fiber; $\mathrm{CO}_{2}$ laser; (Rat)

\section{Introduction}

Since it was first described in 1941 (D'Amour and Smith 1941), the rat tail-flick (TF) test has been widely used as an experimental model of nociception. The test is based on withdrawal of the tail ('tail flick') in response to noxious cutaneous thermal stimulation. This is a spinal reflex (Irwin et al. 1951) that requires both segmental connections and an ascending propriospinal connection from coccygeal and caudal sacral dorsal horn (DH) to motor neurons in the lumbar enlargement (Grossman et al. 1982; Schouenborg and Sjölund 1983). The latency of the reflex is dependent upon 4 variables: (1) time for activation of cutaneous nocicep-

\footnotetext{
* Corresponding author: Peggy J. Danneman, Unit for Laboratory Animal Medicine, University of Michigan Medical School, 018 Animal Research Facility, Ann Arbor, MI 48109-0614, USA. Tel.: (313) 764-0277; FAX: (313) 936-3235.
}

tors by the thermal stimulus; (2) time for afferent conduction of the impulse to the spinal cord DH neurons; (3) conduction within the central nervous system (CNS), or central delay (CD); and (4) time for conduction of the impulse from the ventral horn (VH) to, and activation of, tail muscles. The value of each of these 4 variables is unknown. Participation of $\mathrm{A} \delta$ versus $C$ fibers in activation of the TF reflex is also unknown.

The TF reflex is modulated by supraspinal structures which have excitatory or inhibitory effects on the activity of DH interneurons. Tonic modulation of lamina I neurons is exerted via descending pathways originating in the brain stem (Hall et al. 1982; Morton et al. 1983; Foong and Duggan 1986). Stimulation in nucleus raphe magnus and periaqueductal gray has a predominantly inhibitory effect on nociceptive DH neurons (Duggan and Griersmith 1979; Light et al. 1986). Stimulation of the same areas, among others, strongly in- 
hibits the TF reflex (Zorman et al. 1981; Hentall et al. 1984). Modulation of DH neuronal activity also is implicated in the inhibition of the TF reflex by both exogenous opioid analgesics and endogenous opioid systems (Grossman et al. 1982; Schouenborg and Sjölund 1983; Fields et al. 1988). Delineation of the $\mathrm{CD}$ component of the TF reflex is important because it is only during that phase of the reflex that modulation by descending supraspinal neuronal mechanisms could occur. Hypotheses regarding the mechanisms underlying pain-activated intrinsic analgesia systems on the latency of the TF reflex must take this interval into consideration.

The thermal stimulus generally used in the TF test is a focused beam of intense light or, less commonly, hot water into which the tail is dipped. Although effective in eliciting the reflex, these standard radiantheat stimuli cause asynchronous activation of cutaneous nociceptors. As a result, they cannot be used to measure accurately the duration of each of the components of the reflex. In contrast, the $\mathrm{CO}_{2}$ infrared laser is an effective thermal stimulus which produces synchronous activation of cutaneous nociceptors, a brisk TF reflex, and generation of time-locked evoked potentials (EP). The purpose of this study was to determine the duration of the $\mathrm{CD}$ component of the TF reflex using the $\mathrm{CO}_{2}$ laser as the thermal stimulus.

\section{Methods and materials}

Ten male Sprague-Dawley rats (350-600 g; Charles River) were housed in groups of 4-5, with food and water provided ad libitum. The temperature and relative humidity in the primary enclosure were $72 \pm 2^{\circ} \mathrm{F}$ and $50 \% \pm 20 \%$, respectively. The automatically controlled photoperiod was $12 \mathrm{~h}$ of light $(07: 00-19: 00 \mathrm{~h})$ and $12 \mathrm{~h}$ of dark (19:00-07:00 h).

\section{Testing procedure}

Each rat was gently restrained in a towel, and needle electrodes were inserted into muscles at the base of the tail. The electromyographic (EMG) responses to $\mathrm{CO}_{2}$ laser stimulation $(10 \mathrm{~W}, 45 \mathrm{msec}$ $4.5 \mathrm{~mm}$ beam diameter) were recorded at two points on the tail: one $3-5 \mathrm{~cm}$ proximal to the tip and the other $1-3 \mathrm{~cm}$ distal to the base. For each rat, the points to be stimulated were preselected and marked with a narrow black line upon which the laser beam was centered. Responses to 3-5 stimulations at each point on the tail were averaged to yield TF latencies (TFL) for base and tip. Base and tip TFLs were compared using the paired Student's $t$ test. Stimuli were delivered at $15-30 \mathrm{sec}$ intervals. The distance between the base and tip stimulation sites was measured, and conduction velocity $(\mathrm{m} / \mathrm{sec})$ in the afferent limb of the reflex was calculated as follows:

distance from base to tip ( $\mathrm{mm}$ )

$\overline{\text { tip latency (msec) - base latency ( } \mathrm{msec})}$

Mean conduction velocity was derived by averaging the 10 individual conduction velocities.

Each rat was then anesthetized with sodium pentobarbital $(55$ $\mathrm{mg} / \mathrm{kg}$, i.p.) and instrumented with a jugular catheter and tra- cheostomy tube. A probe was inserted into the rectum so that the animal's temperature could be maintained at $36-37^{\circ} \mathrm{C}$ via a controlled heating pad. The rat was placed in a spinal stereotaxic apparatus, connected to a respirator, and paralyzed with succinyl choline $(2.0 \mathrm{mg} / \mathrm{kg}$, i.v.). The spinal cord from spinal segments $\mathrm{S}_{3}-\mathrm{Co}_{1}$ was exposed by laminectomy and durotomy, then covered with a pool of warm mineral oil. A paraline-coated tungsten microelectrode (impedance: 4-23 $\mathrm{M} \Omega$ ) was inserted into the $\mathrm{DH}$ to a maximum depth of approximately $0.5-1.0 \mathrm{~mm}$. The corresponding receptive field on the tail was located by tapping and stroking of the tail skin. Stainless steel needle electrodes were then inserted subcutaneously within the receptive field. Multiple-unit (bandpass: 1-5 $\mathrm{kHz}$ ) and field-potential (bandpass: $0.1-100 \mathrm{~Hz}$ ) activity in the superficial laminae of the $\mathrm{DH}$ evoked by laser $(10 \mathrm{~W}, 45 \mathrm{msec})$ and electrical $(10 \mathrm{~mA}, 1 \mathrm{msec})$ stimulation of the receptive field were recorded. Stimulation intervals were $15-30 \mathrm{sec}$ for laser stimulation and $2 \mathrm{sec}$ for electrical stimulation. EPs were averaged by computer. a single trial consisting of 8 stimulations (laser) or 16 stimulations (electrical). At the termination of the experiment, DC current $(50)$ $\mu \mathrm{A}, 30 \mathrm{sec}$ ) was passed through the recording electrode to create a small lesion in the DH. The distance from receptive field to $\mathrm{DH}$ recording site was measured and the rat was perfused with $10 \%$ $(w / v)$ formalin. The relevant section of spinal cord was removed, frozen, and cut in $50 \mu$ sections. Sections were stained with cresyl violet for histologic verification of electrode placement in the DH.

\section{Data analysis}

Measurements of EP latency (onset) in the DH following electrical and laser stimulation were used to calculate conduction times $\left(T_{A}\right)$ and conduction velocities in the afferent limb of the TF reflex. Mean conduction velocity for the group was derived by averaging the individual conduction velocities of the 10 rats. The time required for activation of cutaneous nociceptors by the laser $\left(\mathrm{T}_{\mathrm{N}}\right)$ was determined by subtracting the latency of the electrically evoked response from that of the laser-evoked response.

Conduction time in the efferent limb of the $T F$ reflex $\left(T_{E}\right)$ was measured in 3 pentobarbital-anesthetized rats with needle electrodes in the tail flexors. The $\mathrm{VH}$ in the area of $\mathrm{S}_{3}-\mathrm{Co}_{1}$ was stimulated electrically $(50 \mu \mathrm{A}, 1 \mathrm{msec})$ and the latency to onset of the resulting EMG response in the tail recorded.

Conduction time within the CNS, i.e., central delay (CD), was calculated using the formula:

$\mathrm{CD}=\mathrm{TFL}-\left(\mathrm{T}_{\mathrm{N}}+\mathrm{T}_{\mathrm{A}}+\mathrm{T}_{\mathrm{I}}\right)$

TFL in this equation represents estimated flick latency following laser stimulation in the receptive field. For each rat, this time was calculated based on measured flick latency following stimulation near the tail tip, taking into account distance between the receptive field and the tip stimulation site as well as conduction velocity in the afferent limb of the reflex.

\section{Results}

\section{Tail flick latency in awake rats}

Average latency to onset of the TF response (TFL) for the 10 individual rats ranged from 298 to $458 \mathrm{msec}$ following laser stimulation near the base of the tail and from 369 to $520 \mathrm{msec}$ following stimulation near the tip of the tail (Fig. 1). In each animal, TFL following stimulation near the tip was longer than TFL following stimulation near the base. For the group, this difference was statistically significant $(P<0.001)$. Distance 


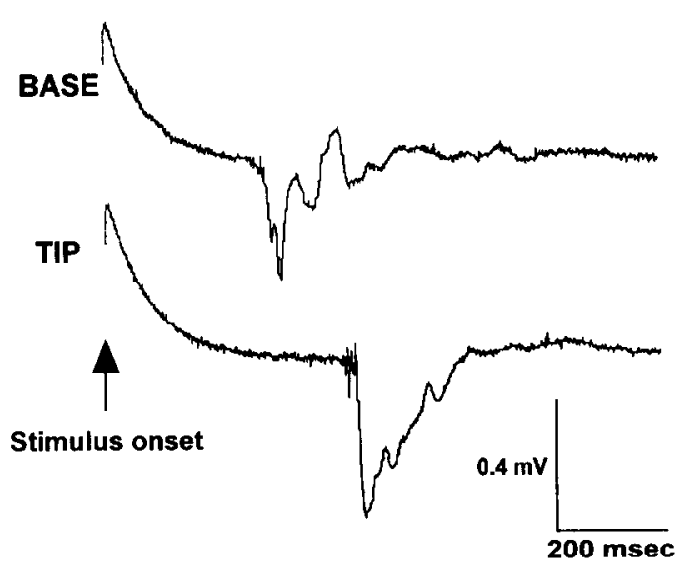

Fig. 1. Typical EMG responses to laser stimulation (10 W, $45 \mathrm{msec}$, $4.5 \mathrm{~mm}$ beam diameter) of an awake rat near the base (top) and tip (bottom) of the tail. EMG recording electrodes were inserted in muscles at the base of the tail.

from base-to-tip stimulation sites ranged from 44 to $115 \mathrm{~mm}$. Based on these measurements, mean conduction velocity for the group was $0.76 \pm 0.11 \mathrm{~m} / \mathrm{sec}$. This is within the $\mathrm{C}$-fiber range.

\section{Afferent conduction time $\left(T_{A}\right)$ and conduction velocity}

Multiple-unit activity and associated EPs were elicited by both electrical and laser stimulation of the tail (Fig. 2). Both unit activity and EPs consisted of early and late components. The latency to onset of the early component ranged from 4 to $18 \mathrm{msec}$ following electrical stimulation and 18 to $31 \mathrm{msec}$ following laser stimulation. The latency to onset of the late component ranged from 147 to $310 \mathrm{msec}$ following electrical stimulation and from 188 to $400 \mathrm{msec}$ following laser stimulation. The variation in latency reflects the variation in distance from the tail receptive field to the recording site in the spinal cord. These results were used to calculate conduction velocity of the afferent input to the DH following laser and electrical stimulation of the tail. Conduction velocity was calculated from the latency of the electrically evoked activity in the $\mathrm{DH}$ and distance from the site of stimulation on the tail to the DH recording site. Distance ranged from 137 to 225 $\mathrm{mm}$ for the 10 animals. Thus mean conduction velocity was $18.64 \pm 2.43 \mathrm{~m} / \mathrm{sec}$ for the early component and $0.74 \pm 0.02 \mathrm{~m} / \mathrm{sec}$ for the late component of the response. These velocities are within the $\mathrm{A}$ and $\mathrm{C}$-fiber ranges, respectively. The conduction velocity estimate for the late $\mathrm{DH}$ evoked response corresponds to the conduction velocity estimate for the afferent component of the laser-evoked $\mathrm{TF}$ reflex $(0.76 \pm 0.11 \mathrm{~m} / \mathrm{sec})$ determined in the awake animals.

\section{Nociceptor activation time $\left(T_{N}\right)$}

The mean difference in latency between the late components of the electrical and laser EPs was $60.00 \pm$

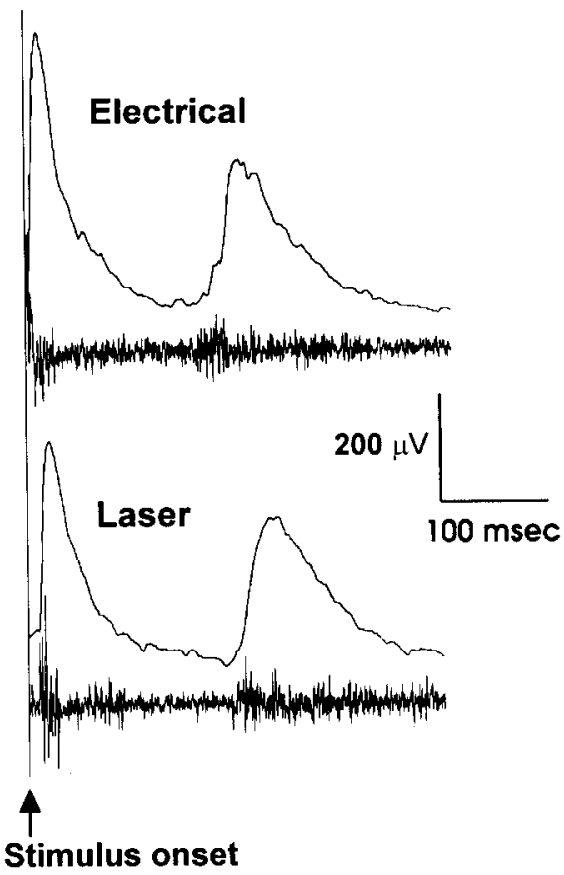

Fig. 2. Multiple unit and EP responses to electrical ( $10 \mathrm{~mA}, 1 \mathrm{msec}, 2$ $\mathrm{sec}$ interstimulus interval) and laser (10 W, $45 \mathrm{msec}, 15-30 \mathrm{sec}$ interstimulus interval) stimulation of the tail in a pentobarbitalanesthetized rat. Responses were recorded in the superficial dorsal horn at $\mathrm{S}_{3}-\mathrm{Co}_{1}$. The unit activity is in response to a single stimulation, whereas the EPs consist of 8 (laser) or 16 (electrical) computeraveraged responses.

7.33 msec. This provides an estimate of the time required for activation of cutaneous nociceptors by the laser.

Efferent conduction time $\left(T_{E}\right)$

Electrical stimulation of the $\mathrm{VH}$ consistently produced an EMG response with a latency at onset of 4 msec. This estimates the time required for efferent conduction from $\mathrm{VH}$ and activation of tail flexors.

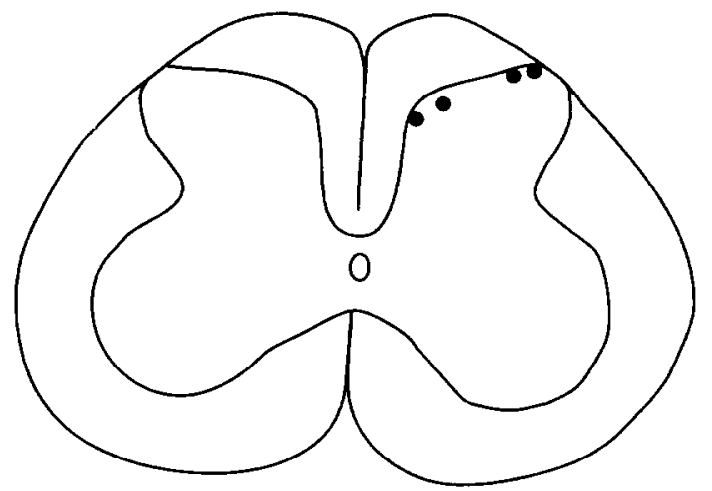

Fig. 3. Spinal cord (spinal segments $\mathrm{S}_{3}-\mathrm{Co}_{1}$ ) showing location of recording electrodes in the 4 experiments in which location was histologically confirmed. DC current $(50 \mu \mathrm{A}, 30 \mathrm{sec})$ was passed through the recording electrode, after which the cord was frozen, sectioned, and stained with cresyl violet. 
('entral delay (CD)

Based on these results, mean CD for the 10 rats was $82.3 \pm 13.08 \mathrm{msec}$. This represented an average of $22 \%$ of the total laser-induced TF time.

\section{Histology}

Location of the recording electrodes in superficial layers of the DH was estimated from stereotaxic coordinates in 6 experiments (high electrode impedance in these cases precluded the creation of visible discrete lesions) and confirmed histologically in the remaining 4 experiments (Fig. 3).

\section{Discussion}

The $\mathrm{CO}_{2}$ infrared laser activates primarily, if not exclusively, small-diameter $C$ polymodal nociceptors and A thermoreceptors (Devor et al. 1982; Isseroff et al. 1982; Arendt-Nielsen and Bjerring 1988a; Pertovalara et al. 1984, 1988). The laser offers one major advantage over standard radiant heat stimuli - an extremely rapid onset of the heating effect with synchronous activation of cutaneous nociceptors. This permits both minimization of tissue damage by the use of very brief stimulus pulses and generation of time-locked evoked potentials (Devor et al. 1982). Synchronous activation of nociceptors permits direct measurement of the time required for the cutaneous nociceptoractivated impulse to travel to the DH. Knowledge of this time, coupled with knowledge of the time required to activate cutaneous nociceptors, the time required for conduction in the efferent linb of the reflex, and total $T F$ lime, made it possible to estimate that the minimal average $C D$ is $82 \pm 13 \mathrm{msec}$.

The time required to activate cutaneous nociceptors by the laser was $60.00 \pm 7.33 \mathrm{msec}$. This is in close agreement with Heavner and Iwazumi (1978) who esti. mated, based on in vitro measurements, that less than $67 \mathrm{msec}$ would be required for the laser to increase skin temperature in the cat to a nociceptive level. In contrast, Devor et al. (1982) found that $147 \pm 63 \mathrm{msec}$ was required for the laser to heat nociceptors in the rat hind paw. The difference could be due to the use of different types of lasers, different stimulation parameters, or differences in properties of the skin of the tail versus that of the hind paw. The stimulation propertics in our study also differed from those of Devor et al. (1982). In the present study, a laser pulse width of 45 msec was effective in activating nociceptors, whereas most cells in the study of Devor et al. (1982) were not activated by pulses less than $80-100 \mathrm{msec}$. This could bc related to differences in laser stimulation parameters $(10 \mathrm{vs} .8 \mathrm{~W})$ or to differences in skin propertics of the hind paw versus the tail. It has been demonstrated that activation of nociceptors by the $\mathrm{CO}_{2}$ laser is highly dependent upon factors such as skin thickness and skin surface conditions such as roughness and water content (Heavner and Iwazumi 1978; Arendt-Niclsen and Bjerring $1988 \mathrm{~b})$

The effect of variations in thickness and surface properties of the tail skin in this study appeared to be minimal. This is suggested by the relatively small coetficient of variation of the nociceptor activation data (0.387). It is suggested also by the similarity in estim mates of afferent conduction velocity in the awake $(0.76 \pm 0.11 \mathrm{msec})$ and anesthetized $(0.74 \pm 0.6 \mathrm{msec})$ rats. Consistent significant differences in nociceptor activation time would have affected estimates of afferent conduction velocity in the awake animals, as these estimates were based on comparisons of TFL following stimulation of the tail near its tip and base.

Of the 4 factors needed to calculate CD, 3 (time required for activation of cutaneous nociceptors, conduction time in the afferent limb of the reflex, and conduction time in the efferent limb of the reflex) were measured in the anesthetized rat, and I (total TF time) was measured in the awake rat. Combining data from the awake and anesthetized rat in this manner was justified based on confirmation that conduction veloc ity in the aflerent limb of the reflex, which was comparable in the awake and anesthetized animals, was not significantly affected by anesthesia. As for the other parameters measured in the anesthetized rats, there is no evidence that pentobarbital anesthesia significantly affects nociceptor activation time, and conduction time in the efferent limb of the reflex was so brief ( $4 \mathrm{msec}$ ) that even a comparatively large anesthetic effect would make little difference in the estimate of $\mathrm{CD}$.

Spinal cord units responsive to laser stimulation of the tail skin were located in the superficial laminac of DH spinal segments $S_{3}-C_{1}$. This is consistent with the findings of Grossman et al. (1982) who reported that the dorsal and ventral nerves innervating the tail skin terminated in spinal segments $\mathrm{S}_{3}-\mathrm{CO}_{3}$.

Based on EMG latency following stimulation of different parts of the tail in the awake rat, we demonstrated that the afferent limb of the laser-activated TF reflex is mediated by fibers conducting in the $C$ range $(0.76 \pm 0.11 \mathrm{~m} / \mathrm{sec})$. Conduction velocity of the electrically induced afferent impulse in the anesthetized rat was nearly identical $(0.74+0.012 \mathrm{~m} / \mathrm{sec})$. Although, in the anesthetized rat, both electrical and laser stimulation also activated A fibers terminating in $\mathrm{DH}$, there was no corresponding carly EMG activity following laser stimulation in the awake rat.

The apparent absence of reflex activity associated with $A$ activation cannot be explained by differences in stimulation parameters, as these were identical in awake and anesthetized rats. It must be assumed. therefore, that $A$ afferents were activated by the laser in the awake as well as the anesthetized animals. Price 
(1972) demonstrated both A- and C-fiber components in EMGs recorded from spinal cats following electrical stimulation of the sural nerve. Schouenborg and Sjölund (1983) also recorded early and late reflex discharges in the common peroneal nerve following electrical stimulation of the sural nerve. The absence of an A-associated component in the laser-evoked TF response may indicate that, although A fibers appear to participate in activating the hind limb flexion reflex, they are ineffective in activating the TF reflex.

Modulation of the $T F$ reflex by a pain-activated supraspinal system would require sufficient time between initial afferent input into the $\mathrm{DH}$ and activation of motor neurons in the $\mathrm{VH}$ for modulation to occur (central delay). Using the infrared $\mathrm{CO}_{2}$ laser, we were able to calculate the temporal constraints on such a process. An average of $22 \%$ of the total laser-induced TF reflex time was accounted for by $C D$. This indicates a limited window during which the laser-induced reflex could be modulated by an intrinsic pain-activated analgesic system. In the case of the laser-evoked TF reflex, conduction to and from the supraspinal site, as well as temporal summation and synaptic delay, would have to take place within approximately $80 \mathrm{msec}$. With standard radiant heat stimuli, where the total reflex latency averages $2-4 \mathrm{sec}$, this window might be considerably longer, but the activation of supraspinal influences also would be delayed. Our estimate of $C D$ is consistent with that of Schouenborg and Sjölund (1983), who reported that $\mathrm{C}$-fiber input to superficial $\mathrm{DH}$ neurons precedes activity in VH motor neurons by at least 20 msec. Factors contributing to $\mathrm{CD}$ include: (1) variable conduction velocities within $\mathrm{C}$ fibers, affecting temporal summation required for activation of $\mathrm{DH}$ cells and $\alpha$-motoneurons; (2) slowing of conduction due to branching of afferents within the spinal cord; and (3) conduction time and synaptic delay involving multiple interneurons within the spinal cord. Because even the laser does not cause perfectly synchronous activation of nociceptors, our estimate of $\mathrm{CD}$ also includes some variability in activation of cutaneous nociceptors. The number of interneurons involved in central processing of the TF reflex is unknown. It is probable that the field potentials we recorded in superficial $\mathrm{DH}$ represented monosynaptic connections of both A- and Cfiber afferents with second-order neurons. This is supported by the close temporal association between the evoked early and late unit activity and the corresponding field potentials. However, following electrical stimulation of the sural nerve in the rat, there was evidence of both monosynaptic C-fiber input to DH lamina II and polysynaptic C-fiber input to lamina V (Schouenborg and Sjölund 1983; Schouenborg 1984). Furthermore, based on their observation that sensory afferent inputs to DH are more caudal in spinal cord than motor efferents originating in $\mathrm{VH}$, Grossman et al.
(1982) concluded that rostral motor neurons must receive propriospinal input from interneurons in more caudal segments. Thus, it appears that multiple interneurons potentially involving multiple spinal segments are involved in the TF reflex pathway. This allows for multiple possible sites of action for modulation by supraspinal analgesic systems.

\section{Acknowledgements}

This work was supported by the Veterans Administration, National Institutes of Health Grants RR00200 and RR00052, and a Bristol-Myers Squibb Award.

\section{References}

Arendt-Nielsen, L. and Bjerring, P., Reaction times to painless and painful $\mathrm{CO}_{2}$ and argon laser stimulation, Eur. J. Appl. Physiol., 58 (1988a) 266-273.

Arendt-Nielsen, L. and Bjerring P., Sensory and pain threshold characteristics to laser stimuli, J. Neurol. Neurosurg. Psychiat., 51 (1988b) 35-42

D'Amour, F.E. and Smith, D.L., A method for determining loss of pain sensation, J. Pharmacol. Exp. Ther., 72 (1941) 74-79.

Devor, M., Carmon, A. and Frostig, R., Primary afferent and spinal sensory neurons that respond to brief pulses of intense infrared laser radiation: a preliminary survey in rats, Exp. Neurol., 76 (1982) 483-494.

Duggan, A.W. and Griersmith, B.T., Inhibition of the spinal transmission of nociceptive information by supraspinal stimulation in the cat, Pain, 6 (1979) 185-189.

Fields, H.L., Barbaro, N.M. and Heinricher, M.M., Brain stem neuronal circuitry underlying the antinociceptive action of opiates. In: H.L. Fields and J.-M. Besson (Eds.), Progress in Brain Research, Vol. 77, Pain Modulation, Elsevier, New York, 1988, pp. 245-257.

Foong, F.W. and Duggan, A.W., Brainstem areas tonically inhibiting dorsal horn neurons: studies with microinjection of the GABA analogue piperidine-4-sulphonic acid, Pain, 27 (1986) 361-372.

Grossman, M.L., Basbaum, A.I. and Fields, H.L., Afferent and efferent connections of the rat tail flick reflex (a model used to analyze pain control mechanisms), J. Comp. Neurol,, 206 (1982) 9-16.

Hall, J.G., Duggan, A.W., Morton, C.R and Johnson, S.M., The location of brain stem neurones tonically inhibiting dorsal horn neurons of the cat, Brain Res., 244 (1982) 215-222.

Ileavner, J.E. and Iwazumi, T., A laser system for stimulating spinal neuron receptive fields, Brain Res., 152 (1978) 348-352.

Hentall, I.D., Zorman, G., Kansky, S. and Fields, H.L., An estimate of minimum number of brain stem neurons required for inhibition of a flexion reflex., J. Neurophysiol, 51 (1984) 978-985.

Irwin, S., Houde, R.W., Bennett, D.R., Hendershot, L.C. and Seevers, M.H., The effects of morphine, methadone and meperidine on some reflex responses of spinal animals to nociceptive stimulation, J. Phannacol. Exp. Ther., 101 (1951) 132-143.

Isseroff, R.G., Sarne, Y., Carmon, A. and Isseroff, A., Cortical potentials evoked by innocuous tactile and noxious thermal stimulation in the rat: differences in localization and latency, Behav. Neural. Biol., 35 (1982) 294-307.

Light, A.R., Casale, EJ. and Menetrey, D.M., The effects of focal stimulation in nucleus raphe magnus and periaqueductal gray on 
intracellularly recorded neurons in spinal laminae I and II. J. Neurophysiol., 56 (1986) 555-571.

Morton, C.R., Johnson, S.M. and Duggan, A.W., Lateral reticular regions and the descending control of dorsal horn neurones of the cat: selective inhibition by electrical stimulation, Brain Res., 275 (1983) 13-21.

Pertovaara, A., Morrow, T.J. and Casey, K.L., Cutaneous pain and detection thresholds to short $\mathrm{CO}_{2}$ laser pulses in humans: evidence on afferent mechanisms and the influence of varying stimulus conditions, Pain, 34 (1988) 261-269.

Pertovaara, A., Reinikainen, K. and Hari, R., The activation of unmyelinated or myelinated afferent fibers by brief infrared laser pulses varies with skin type, Brain Res., 307 (1984) 341-343.
Price, D.D., Characteristics of second pain and flexion reflexes indicative of prolonged central summation, Exp. Neurol., 37 (1972) 371-387

Schouenborg, J. and Sjölund, B.H., Activity evoked by A- and C-afferent fibers in rat dorsal horn neurons and its relation to a flexion reflex, J. Neurophysiol., 50 (1983) 1108-1121.

Schouenborg, J., Functional and topographical properties of field potentials evoked in rat dorsal horn by cutaneous $\mathrm{C}$-fiber stimulation, J. Physiol., 356 (1984) 169-192.

Zorman, G., Hentall, I.D., Adams, J.E. and Fields, H.L., Naloxonereversible analgesia produced by microstimulation in the medulla, Brain Res.. 219 (1981) 137-148. 